Check for updates

Cite this: Chem. Sci., 2018, 9, 8753

๑ All publication charges for this article have been paid for by the Royal Society of Chemistry

Received 30th May 2018

Accepted 18th September 2018

DOI: $10.1039 / \mathrm{c} 8 \mathrm{sc} 02370 \mathrm{k}$

rsc.li/chemical-science

\section{Synthesis of aryl-thioglycopeptides through chemoselective Pd-mediated conjugation $\uparrow$}

\author{
David Montoir, ${ }^{a}$ Mehdi Amoura, ${ }^{\mathrm{b}}$ Zine El Abidine Ababsa, ${ }^{a}$ T. M. Vishwanatha, ${ }^{\mathrm{b}}$ \\ Expédite Yen-Pon, ${ }^{a}$ Vincent Robert, ${ }^{c}$ Massimiliano Beltramo, ${ }^{c}$ Véronique Piller, ${ }^{b}$ \\ Mouad Alami, (D) ${ }^{a}$ Vincent Aucagne (D) ${ }^{* b}$ and Samir Messaoudi (D) *a
}

\begin{abstract}
We describe herein a Pd-catalyzed methodology for the thioglycoconjugation of iodoaryl peptides and aminoacids. This operationally simple process occurs under semi-aqueous conditions and displays wide substrate scope. The strategy has been successfully applied to both the thioglycosylation of unprotected peptides and the generation of thioglyco-aminoacid building blocks, including those suitable for solid phase peptide synthesis. To demonstrate the broad potential of this technique for late stage functionalization, we successfully incorporated challenging unprotected $\beta$-S-GlcNAc- and $\alpha$-S-GalNAcderivatives into very long unprotected peptides. This study opens the way to new applications in chemical biology, considering the well-recognized advantages of S-glycosides over $O$-glycosides in terms of resistance towards both enzymatic and chemical degradation.
\end{abstract}

Thioglycosides are attractive substitutes for $O$-glycosides as they are resistant to enzymatic cleavage and less susceptible to chemical degradation. ${ }^{1}$ In the past three decades, there has been a significant growth in the synthesis of thioanalogues of naturally-occurring $O$-glycosides such as oligosaccharides ${ }^{2}$ and glycolipids. ${ }^{3}$ Most of the tested thioglycosides showed enhanced biological activities, presumably arising from their resistance to glycosidases combined with an isosteric relationship between thioether and ether bonds. In this context, $S$-linked glycopeptides have emerged as promising tools for the biological study of $O$-glycosylated peptides and proteins and are recognized as very good structural mimics. ${ }^{4,5}$ As proofs-of-concept, the thioglycoside analogue of the post-translational modification (PTM) $O-\beta$-D- $N$-acetylglucosamine (GlcNAc), attached to a cysteine residue instead of serine, was used to examine the effect of $O$ GlcNAcylation on casein kinase $\mathrm{II}^{6}$ and $\alpha$-synuclein, ${ }^{4}$ through the total synthesis of the full length proteins. In similar ways, thioanalogues of the tumor-associated Tn antigen, D- $N$-acetylgalactosamine (GalNAc) $\alpha$-O-linked to serine or threonine, have been synthesized for structural immunology studies, ${ }^{5}$ and thioanalogues of $O$ - $\beta$-GlcNAc-containing antimicrobial peptide glycocin F showed improved bacteriostatic activities. ${ }^{7}$ Cysteine

${ }^{a}$ BioCIS, Univ. Paris-Sud, CNRS, Univ. Paris-Saclay, Châtenay-Malabry, France. E-mail: samir.messaoudi@u-psud.fr; Tel: +330146835887

${ }^{b}$ Centre de Biophysique Moléculaire, CNRS, Orléans, France. E-mail: aucagne@ cnrs-orleans.fr; Tel: +330238255577

'UMR Physiologie de la Reproduction et des Comportements, INRA, CNRS, Univ. Tours, IFCE, Nouzilly, France

$\dagger$ Electronic supplementary information (ESI) available: General, experimental procedures, and characterization of all new compounds. See DOI: $10.1039 / \mathrm{c} 8 \mathrm{sc} 02370 \mathrm{k}$
$S$-glycosylation has also been recently identified as a naturally occurring PTM in several bacteriocins ${ }^{7,8}$ and was lately found in mammalian proteins. ${ }^{9}$

From a synthetic chemistry point of view, glycosyl thiols have become useful building blocks for the synthesis of $S$-linked glyco-aminoacids, glycopeptides and glycoproteins, exploiting the exceptional nucleophilicity of the thiol group. Glycosyl thiols can react chemoselectively through conjugate addition, ${ }^{10}$ nucleophilic substitution of halogenides ${ }^{11}$ ring opening of aziridines ${ }^{12}$ and cyclic sulfamidates, ${ }^{13}$ or disulfide formation followed by a desulfurative rearrangement. ${ }^{14}$ Conversely, reaction of the thiol group of cysteine with a carbohydrate derivative through nucleophilic substitution of glycosyl bromides, ${ }^{15}$ free radical thiol-ene coupling ${ }^{16}$ or Ferrier reaction ${ }^{17}$ has also been described. While these methods have provided robust access to $S$-linked glycopeptides, in most cases the sugar moiety is attached to the peptide through cysteine or sometimes homocysteine residues. Strikingly, to the best of our knowledge there is no report concerning $S$-linked glycopeptides analogues of $O$ glycosylated tyrosines, ${ }^{18}$ despite the relevance of such compounds for glycobiological investigations. Tyrosine $O$ glycosylation, ${ }^{19}$ is indeed a rather underexplored PTM, and $O$ GalNAc Tyr residues were identified only recently in human ${ }^{20}$ and in murine proteins. ${ }^{21}$ Although this modification is rare, it was found associated with pathogenic conditions for the amyloid precursor protein (APP) in Alzheimer's disease. Characterizing the $O$-glycosylation landscape of human plasma, platelets and endothelial cells also showed the presence of such $O$-GalNAc Tyr linkages in several proteins involved in hemostasis. ${ }^{22}$ Very recently, pathogenic bacteria toxins able to inactivate eukaryotic Rho GTPases by catalyzing the $O$ - 
GlcNAcylation of a Tyr residue have also been characterized. ${ }^{23}$ These recent findings prompted us to develop synthetic routes to $O$-glycotyrosine thioanalogues, by either preparing glycosylaminoacid building blocks suitable for peptide synthesis, or using a post-synthetic protocol based on the glycoconjugation of unprotected peptide under aqueous conditions. Both approaches are based on the reaction of para-iodophenylalanine ( $p$-IPhe) residues with glycosyl thiols using highly chemoselective Pd-catalysis conditions.

In our efforts to functionalize sugars under transition-metal catalysis, ${ }^{24}$ we recently reported an efficient protocol for the palladium-catalyzed coupling of aryl halides with various $\alpha$-and $\beta$-glycosyl thiols. ${ }^{25}$ The $\mathrm{C}-\mathrm{S}$ bond-forming reaction was achieved within minutes at room temperature by using $\mathrm{G}_{3}$-XantPhos palladacycle pre-catalyst ${ }^{26}(1 \mathrm{~mol} \%)$, in the presence of $\mathrm{Et}_{3} \mathrm{~N}$ in THF. In order to expand the synthetic utility of this transformation onto more complex systems such as peptides and proteins, we herein extend the scope of this reaction for (i) the preparation of glycoaminoacid building blocks (ii) the late stage functionalization of unprotected peptides under aqueous conditions and (iii) application to a wide variety of protected and unprotected glycosyl thiols. In particular we demonstrate for the first time the application of this chemistry to the reputedly challenging 2-deoxy-2- $N$-acetamido sugar $\alpha$ thioGalNAc.

This work thus opens unprecedented opportunities for chemical glycobiology studies of tyrosine glycosylation through precise oxygen-to-sulfur substitution. Besides such possible application, we also showed the utility of this straightforward methodology for the synthesis of various complex neoglycoconjugates, a growing area of research where the saccharide moiety can be exploited to modulate the bioactivity or physicochemical properties of a given peptide or protein. ${ }^{27}$

To establish the appropriate conditions for the coupling reaction, tetra- $O$-acetylated 1 -thio- $\beta$-D-glucopyranose $\mathbf{1 a}$ and $N$ Boc-DL-4-iodophenylalanine 2 a were initially selected as model coupling substrates (for the optimization of the reaction conditions see ESI $\dagger$ ). A full conversion and 96\% yield of isolated product 3a was obtained using $3 \mathrm{~mol} \%$ of $\mathrm{G}_{3}$-XantPhos catalyst. ${ }^{28}$ Taking into account that suitable conditions for peptides and proteins functionalization include aqueous media and ambient temperature, we performed the coupling of 1a with $\mathbf{2 a}$ in different aqueous media (see ESI $\dagger$ for details). Thus, conducting the coupling reaction in $\mathrm{THF} / \mathrm{H}_{2} \mathrm{O}(1: 2)$ afforded $3 \mathrm{a}$ in

Table 1 Scope of the coupling of aminoacids $2 \mathrm{a}-\mathrm{f}$ with various 1 -thiosugars $1 \mathrm{a}-\mathrm{h}^{a}$

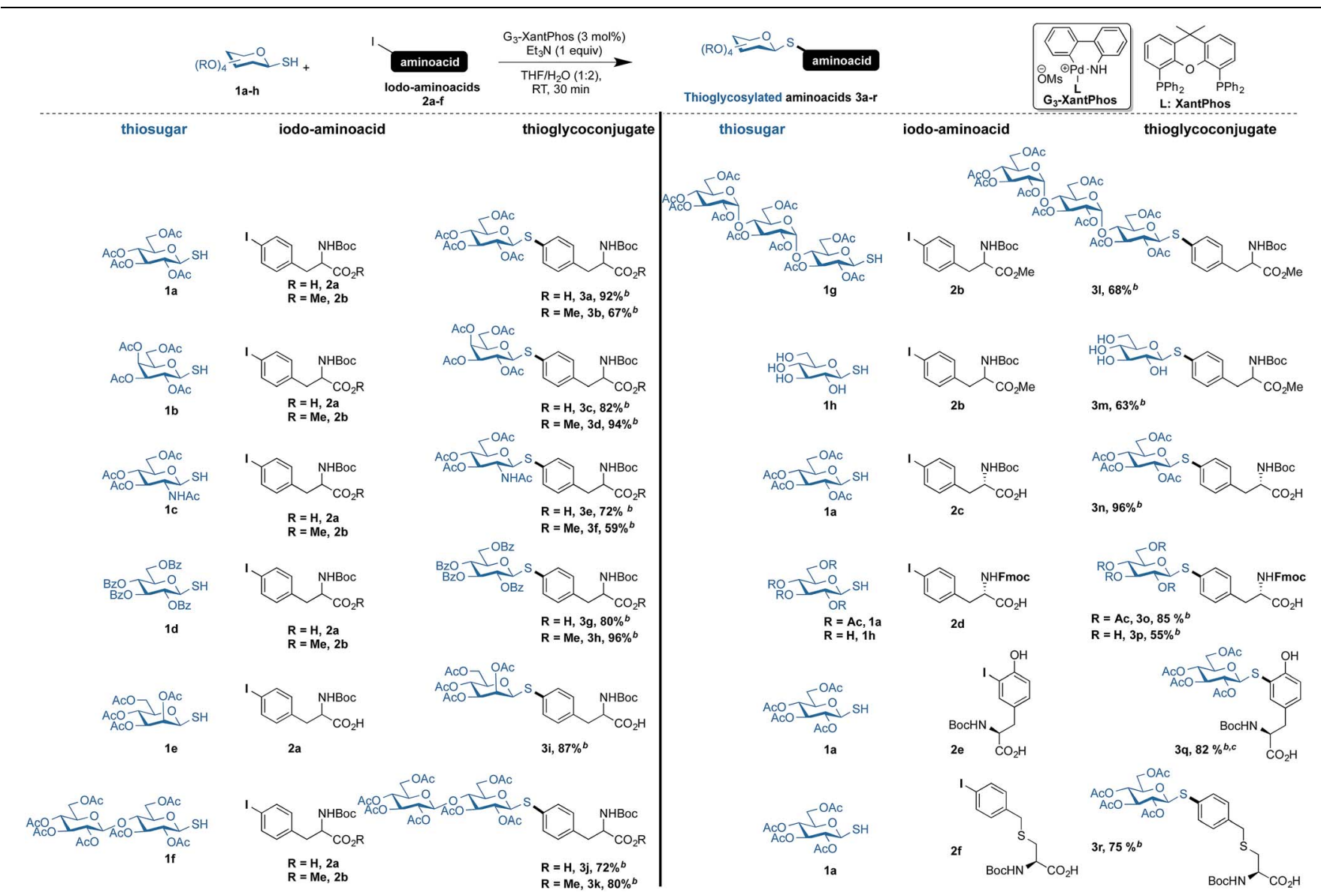

${ }^{a}$ Reaction of thiosugars 1a-h $\left(0.27\right.$ mmol, 1 equiv.), iodo-aminoacids 2 a-f (1 equiv.) and $\mathrm{G}_{3}$-XantPhos precatalyst (3 mol\%). ${ }^{b}$ Yield of isolated product. ${ }^{c} 3$ equiv. of thiosugar 1 a were used. 
an excellent yield of $92 \%$ (see ESI $\dagger$ ). Motivated by this watertolerant coupling procedure, we next expanded the scope of this Pd-catalyzed coupling of structurally diverse $\alpha$ - and $\beta$-thiol derivatives of mono-, di- and tri-saccharides with various amino acids 2a-f (Table 1). All the coupling reactions proceeded in good yields and without epimerization at anomeric position. ${ }^{29}$ In addition to 1a, tetra- $O$-acetylated 1 -thio- $\beta$-D-galactopyranose 1b, tri-O-acetylated $N$-Ac-1-thio- $\beta$-D-glucosaminopyranose 1c, tetra- $O$-benzoylated 1-thio- $\beta$-D-glucopyranose $1 \mathbf{d}$ and tetra- $O$ acetylated 1-thio- $\beta$-D-mannopyranose 1e were efficiently coupled with both $N$-Boc-DL- $p$-iodophenylalanine 2a and its methyl ester $\mathbf{2 b}$ to give the corresponding thioglycoconjugates 3a-p in good yields. A slightly lower yield was observed with 1c as nucleophilic partner to give thioglycosylated amino acids $\mathbf{3 e}$ and 3 f in $72 \%$ and $59 \%$ yields, respectively. Moreover, the reaction is not limited to monosaccharides, but can be applied to more complex di- and trisaccharide derivatives. Thus, hepta$O$-acetylated 1-thio- $\beta$-D-cellobiose 1 ff and deca- $O$-acetylated 1thio- $\beta$-D-maltotriose $\mathbf{1 g}$ were reacted with $\mathbf{2 a}$ or $\mathbf{2 b}$ to give corresponding glycoconjugates $\mathbf{3} \mathbf{j}-\mathbf{l}$ in good yields. Noteworthy the reaction works also well with unprotected sugars. As an example, the reaction of $2 \mathbf{b}$ with 1 -thio- $\beta$-D-glucose $1 \mathbf{h}$ afforded product $3 \mathrm{~m}$ in a satisfactory $63 \%$ yield and with a total retention of the $\beta$-anomeric configuration as confirmed from the distinct $J_{1,2}$ coupling of $9.7 \mathrm{~Hz}$. $1 \mathrm{a}$ and $\mathbf{1 h}$ were readily coupled with the L-enantiomer of Fmoc-p-iodo-phenylalanine 2d to furnish 30 and $3 \mathbf{p}$ in good yields. Interestingly, the latter compounds are two building blocks suitably protected for their use in Fmocbased SPPS. In addition to para-iodophenylalanine derivatives, $N$-Boc-3-iodo-D-tyrosine $2 \mathrm{e}$ as well as $N$-Boc $p$-iodobenzyl $\mathrm{L}^{-}$ cysteine $2 \mathrm{f}$ were used successfully in this coupling to furnish thioglycoconjugates $\mathbf{3 q}, \mathbf{r}$ in $82 \%$ and $75 \%$ yields, respectively.

Having demonstrated the excellent catalytic activity of the $\mathrm{G}_{3}$-XantPhos pre-catalyst with aminoacids, we next turned our attention to the generalization of the method with respect to IPhe-containing $N$-Boc protected di- and tripeptides (Table 2). In all cases studied, the coupling reactions proceeded selectively and cleanly in high yields (glycoconjugates 5a-f). The established $\mathrm{C}-\mathrm{S}$ bond formation protocol is compatible with the indole $\mathbf{N H}$ of tryptophan (5b), phenol of tyrosine (5c and $\mathbf{5 f}$ ) and carboxylic acids (5e), indicating a large tolerance towards functional groups.

To open a complementary synthetic pathway towards larger thioglycopeptides, we next assessed the suitability of the synthesized building blocks in standard Fmoc-based SPPS protocols. For a proof-of-concept, we selected lipotriazolopeptide 6a, a synthetic derivative of kisspeptin-10 (KP10), an endogenous neuropeptide playing a pivotal role in the central control of the reproductive system in mammals and non-bird vertebrates. KP10 acts through the activation of its cognate G-protein-coupled receptor, KiSS1R. KP10 has a very short half-life in blood ( $<1 \mathrm{~min}$ ) and $\mathbf{6 a}$ was rationally designed with the aim to overcome this limitation, by including both a 1,4-disubstituted 1,2,3-triazole as a protease-resistant amide bond surrogate ${ }^{30}$ to improve metabolic stability and an $N$-palmitoylated isoglutamate albumin-binding motif to decrease renal excretion. ${ }^{31}$ 6a shows a dramatically enhanced in vivo
Table 2 Scope of the coupling of $\beta$-thioglucose 1 a with various 1-diand tripeptides $4 a-f^{a}$

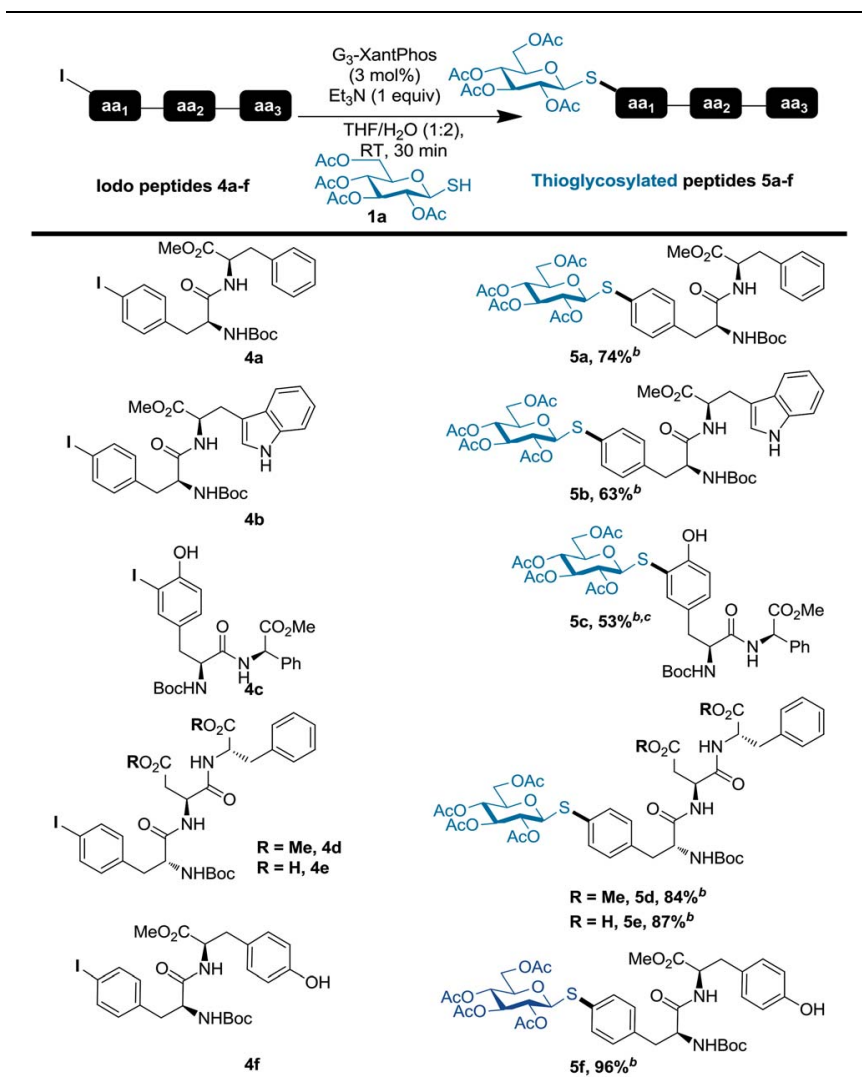

${ }^{a}$ Reaction of $\beta$-thioglucose $1 \mathrm{a}(0.16-0.27 \mathrm{mmol}, 1$ equiv.), iodo-peptides 4a-f $\left(1\right.$ equiv.) and XantPhos $\mathrm{PdG}_{3}$ precatalyst $(3 \mathrm{~mol} \%) .{ }^{b}$ Yield of isolated product. ${ }^{c}$ The reaction was stirred during $4 \mathrm{~h}$.

activity as compared with KP10, while also benefiting from an increased in vitro potency towards KiSS1R. We chose the Tyr1 residue (KP10 numbering), that as has been shown by Alascanning to be tolerant to modifications, to incorporate a model $\beta$-thioglucosyl analogue. ${ }^{32,33}$ Note that, as many lipopeptides, 6a shows very limited solubility under aqueous conditions, and is prone to hydrogel formation such as the

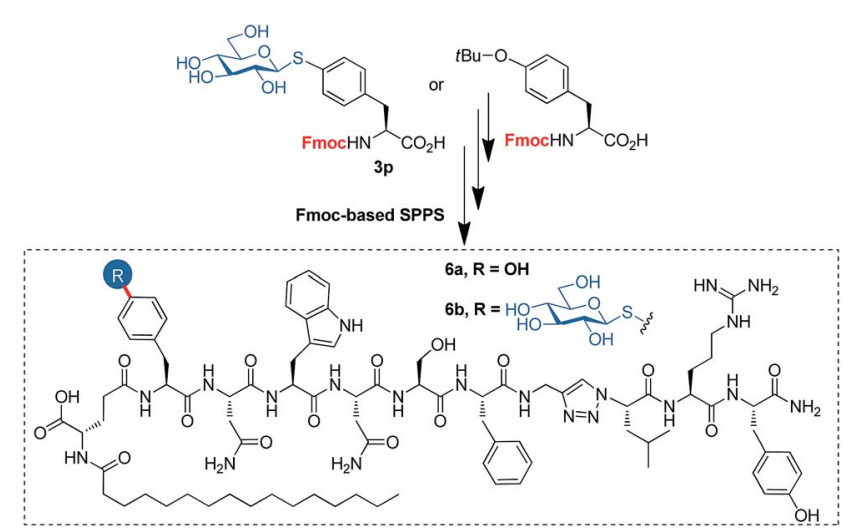

Fig. 1 Lipo-triazolopeptide analogue $6 a$ of the neuropeptide KP10, and its thioglucosylated derivative $6 \mathrm{~b}$. 

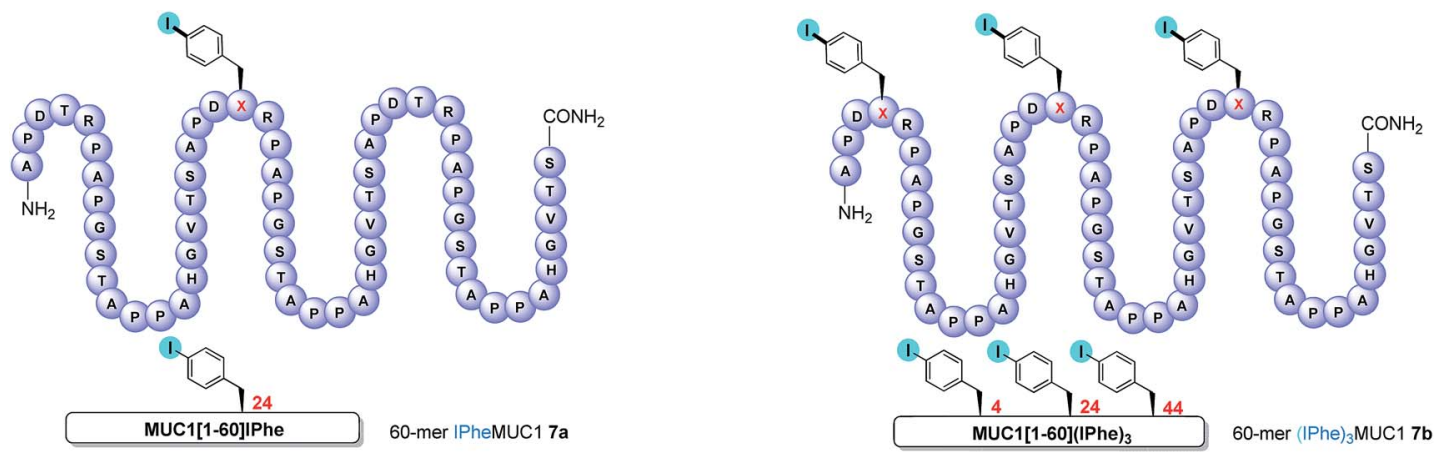

Fig. 2 Schematic representations of MUC1-derived mono-iodo peptide 7a and tri-iodo peptide $7 \mathrm{~b}$. X = p-iodophenylalanine.

parent KP10. ${ }^{34}$ Our choice of this peptide as a model compound was in part driven by our curiosity to see if glycoconjugation could improve its physicochemical properties.

The use of the building block $\mathbf{3 p}$, instead of a standard SPPS Fmoc-Tyr $(t \mathrm{Bu})-\mathrm{OH}$ furnished the expected thioglyco-lipotriazolopeptide $\mathbf{6 b}$ in similar yields as for $\mathbf{6 a}$ (Fig. 1). This demonstrates the compatibility of our thioglycoaminoacid building block with standard Fmoc-SPPS protocols, including couplings, piperidine-mediated Fmoc deprotections and TFAbased cleavage. $\mathbf{6 b}$ was tested for its agonist activity towards KiSSR, and showed similar activity $\left(\mathrm{EC}_{50}=0.03-0.3 \mathrm{nM}\right)$ as compared with 6a $\left(\mathrm{EC}_{50} 0.02-0.2 \mathrm{nM}\right.$, mean and $95 \%$ confidence interval). Physicochemical properties of $\mathbf{6 b}$ were also briefly evaluated. However, no marked differences were observed as compared to 6a: the glycopeptide is not soluble in water at a concentration of $0.1 \mathrm{mM}$, and slowly forms a gel after solubilization in DMSO followed by dilution with water $(0.1 \mathrm{mM}$ final concentration, $95: 5$ water/DMSO).

To assess the utility of our palladium-catalyzed procedure in the synthesis of very long thioglycopeptides through post-SPPS thioglycosylation, we next investigated the synthesis of analogues of the human mucin MUC1. MUC1 is a densely $O-$ glycosylated glycoprotein produced as a membrane-anchored as well as a soluble form, both expressed by many epithelial cells. Their highly enhanced expression by many tumor cells types is accompanied by their aberrant glycosylation giving rise to largely reduced $O$-glycan chain complexity and density. Therefore, tumor-associated carbohydrate antigens such as Tn and its sialylated form (STn), are frequently found on epithelial tumor cells and are considered as clinically relevant tumor markers. ${ }^{35}$ The extracellular and soluble domains of MUC1 proteins contain a variable number of tandem repeat sequences of 20 amino acids (APDTRPAPGSTAPPAHGVTS), ${ }^{36}$ each presenting 5 potential $O$-glycosylation sites. ${ }^{37}$ Thus, Tn antigens on MUC1 act as a signature associated with cancer ${ }^{38}$ and represent promising targets for the development of synthetic antitumor vaccines. ${ }^{39}$ However, many attempts to produce MUC1-based anticancervaccines illustrated the very low immunogenicity of the natural MUC1 glycoprotein. It is thus necessary to generate analogues of MUC1 to improve the immune response against the native oncogenic glycoprotein. As an example, unnatural derivatives were recently synthesized by incorporation of a linker placed between the peptide and the $\alpha$-GalNAc moiety, in order to favor the presentation of the sugar for molecular recognition events. ${ }^{40}$ The crystal structure of major histocompatibility complex-I (MHC-I) with such a linker-containing neoglycopeptide indeed showed that while the aglycone part of the antigen binds to the MHC, the carbohydrate moiety can facilitate the recognition of T-cell receptors (TCR) and therefore stimulate immune response. ${ }^{41}$ Here, we propose to produce new MUC1 mimics in which the GalNAc moieties would also be distant from the peptide chain and could thus present novel properties interesting for the production of cancer vaccines.

We first examined the coupling reactions between tri- $O$ acetylated $\beta$-thio-GlcNAc 1c, its unprotected congener $1 \mathbf{i}$ and $\alpha-$ thioGalNAc $1 \mathbf{j}$ with two fully-unprotected modified 60-aminoacid sequences of MUC1 (e.g. 3 tandem repeats) in which threonine residues of the immunogenic APDTR sequence were replaced by $p$-iodo-s-phenylalanine in position 24 (mono-iodo peptide 7a, Fig. 2) or in positions 4,24 and 44 (tri-iodo peptide $\mathbf{7 b}$ ).

First attempts were initiated to find optimal conditions for Pd-catalyzed coupling with mono-iodo peptide MUC1 7a (1 $\mathrm{mM})$. O-Acetylated $\beta$-thioGlcNAc $1 \mathrm{c}$ was used as the model thiosugar. It was found that the quantity of $\mathrm{G}_{3}$-XantPhos reagent is crucial as the use of almost 5 equivalents was required to obtain a complete conversion of the starting material over $1 \mathrm{~h}$. Under these conditions thioglycoconjugate $\mathbf{8 a}$ was isolated in an excellent $80 \%$ yield (Fig. 3). Notably, coupling of unprotected $\beta$ thioGlcNAc 1i with 7a under these conditions furnished exclusively $\mathbf{8 b}$ without any detectable peptide side products (Fig. 3). Finally, peptide $8 \mathbf{c}$ bearing $\alpha$-thioGalNAc was obtained by coupling of the challenging and unstable $\alpha$-GalNAc thiol $\mathbf{1 j}$ with $7 \mathbf{a}$ in a good yield. These selective thioglycosylations of MUC1derived mono-iodopeptide 7a represent an important preliminary result in view of modifying more complex peptides and proteins. These promising results encouraged us to investigate this coupling reaction with the tri-iodo peptide $7 \mathbf{b}$ (Fig. 2). This coupling was effective in all cases to produce conjugates $\mathbf{8 d - f}$ in good yields.

In order to characterize, from a biochemical point of view, the obtained thioglycopeptides we next verified if the thioGalNAc-containing $\mathbf{8 c}$ and $\mathbf{8 f}$ could be recognized by an $O$-GalNAc-specific lectin. For that purpose, we conjugated 


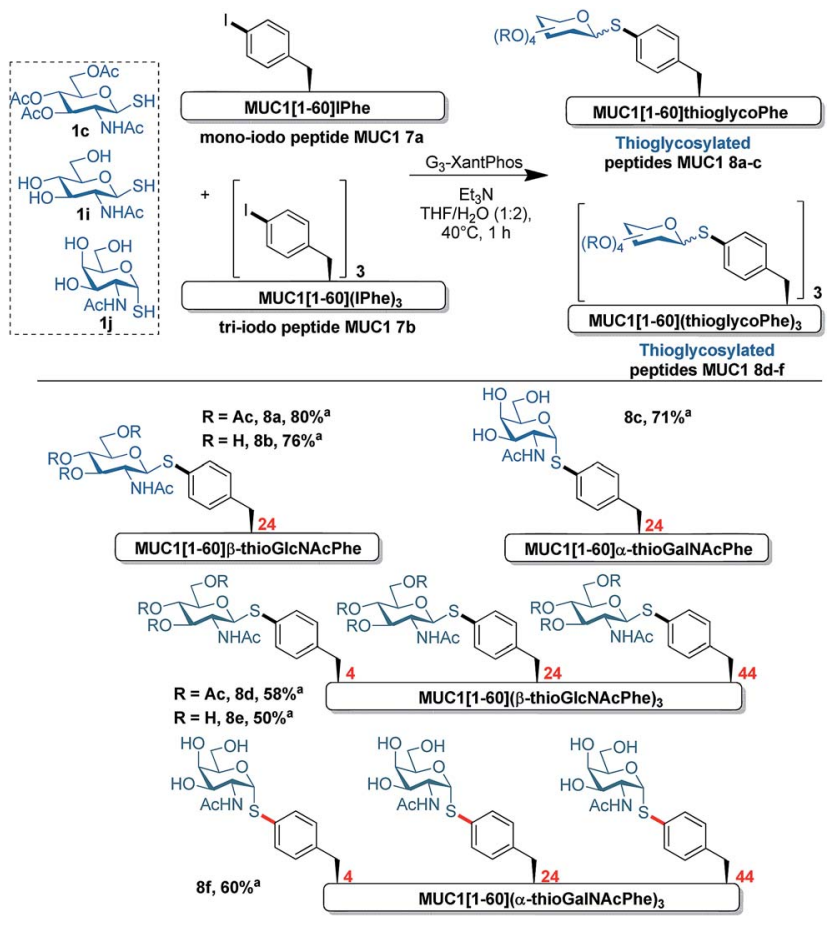

Fig. 3 Pd-catalyzed thioglycoconjugation of MUC1-derived monoiodo peptide $7 \mathrm{a}$ and tri-iodo peptide $7 \mathrm{~b}$ with $1 \mathrm{c}, 1 \mathrm{i}$ and $1 \mathrm{j}$. ${ }^{\text {al }}$ Isolated yield.

a biotin moiety at the N-terminus of each thioglycopeptide $\mathbf{8 c}$ and $\mathbf{8 f}$ as well as on iodopeptides $7 \mathbf{a}$ and $\mathbf{7 b}$ used as negative controls (see ESI $\dagger$ for details). ${ }^{42}$ The biotinylated MUC1 analogues were efficiently immobilized on NeutrAvidincoated plates in a quantitative and saturable manner, as judged through recognition by specific anti MUC1 antibodies (see ESI† for details).

We then checked if the Vicia villosa plant lectin (VVL) specific for $\alpha$ - or $\beta$-linked terminal $O$-GalNAc could still recognize the GalNAc-thioglycopeptides. The results of our ELISA assays,

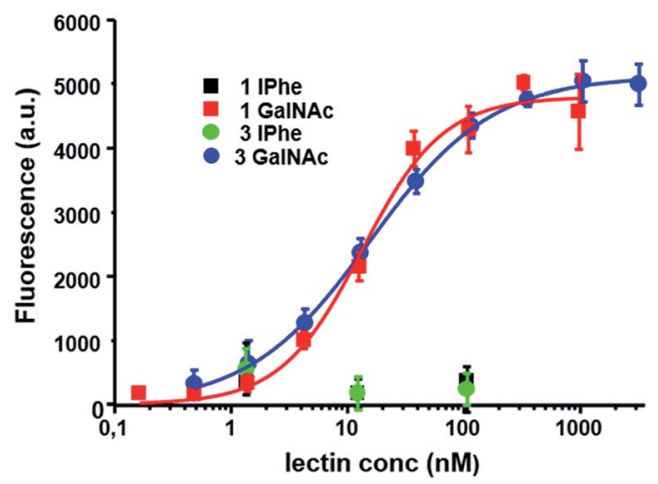

Fig. 4 ELISA-based assays showing FITC-labelled VVL binding of the different peptides and glycopeptides tested. The fluorescence values are the means of three independent experiments realized at the same peptide concentration and error bars indicate the standard deviation. Apparent $K_{\mathrm{d}}$ values were determined from assays at different peptide concentrations (see ESI† for details). presented in Fig. 4, show efficient lectin binding since the apparent $K_{\mathrm{d}}$ was $26.0 \pm 7.3 \mathrm{nM}$ for the mono-GalNAc thioglycopeptide (biotinylated 8c) and $27.2 \pm 12.1 \mathrm{nM}$ for the triGalNAc thioglycopeptide (biotinylated 8f). Such values are in very good agreement with those recently obtained on $O$-GalNAcTyr containing glycopeptides ${ }^{\mathbf{4 3}}$ with apparent $K_{\mathrm{d}}$ values ranging from $1.4 \pm 0.1$ to $243 \pm 113 \mathrm{nM}$ for neoglycoproteins showing different GalNAc densities. In our work the two thioglycopeptides tested gave roughly similar apparent $K_{\mathrm{d}}$ values indicating no effect on the lectin binding of the GalNAc density ( 1 vs. 3 GalNAc per peptide). These VVL binding results suggest the usefulness of our simple synthetic strategy in order to produce thioglycopeptides which could be used as mimics of Tyr-GalNAc containing peptides.

\section{Conclusions}

In conclusion, we have developed a highly chemoselective and efficient method to access a wide range of complex thioglycopeptides using the powerful palladacycle pre-catalyst $\mathrm{G}_{3}$ XantPhos. This protocol provides a straightforward method to access thioglyco-aminoacid building blocks and for the latestage thioglyco functionalization of unprotected peptides. An iodophenyl "tag" positioned using the non-natural amino acid $p$-IPhe allows post-synthetic site-selective thioglycoconjugation of a MUC1-derived peptide using $\beta$-S-GlcNAc and $\alpha$-S-GalNAc thiosugars. The reaction is compatible with nearly all natural amino acids, which are inert under these conditions (at the exclusion of free thiol cysteine). Since several methods have been developed for the incorporation of $p$-iodophenylalanine residues in recombinant proteins, ${ }^{44}$ these results also pave the way to more complex and larger thioglycoproteins, through semi-synthesis approaches. We expect this simple and general protocol to be of broad utility for the development of new tools to explore and modulate biological systems, in particular for the study of tyrosine $O$-glycosylation, a recently emerging field of investigation. Interestingly, while we were preparing this manuscript, a very complementary methodology was reported for chemoselective tyrosine $O$-glycosylation through $\mathrm{Ca}(\mathrm{OH})_{2}$ mediated coupling of unprotected peptides with glycosyls fluorides. ${ }^{45}$

\section{Conflicts of interest}

There are no conflicts to declare.

\section{Acknowledgements}

Authors acknowledge support of this project by ANR (ANR-15CE29-0002 CarNuCat, ANR-15-CE07-0022 Easyminiprot and ANR-15-CE20-0015 KISS projects), Région Centre-Val-de-Loire (Capriss projet), CNRS, University Paris Sud and by la Ligue Contre le Cancer through an Equipe Labellisée 2014 grant. BioCIS laboratory is a member of the Laboratory of Excellence LERMIT supported by a grant (ANR-10-LABX-33). 


\section{Notes and references}

1 For reviews on thioglycosides, see: (a) H. Driguez, Top. Curr. Chem., 1997, 187, 85-116; (b) H. Driguez, ChemBioChem, 2001, 2, 311-318; (c) K. Pachamuthu and R. R. Schmidt, Chem. Rev., 2006, 106, 160-187; (d) G. Lian, X. Zhang and B. Yu, Carbohydr. Res., 2015, 403, 13-22.

2 For representative examples, see: (a) B. Aguilera and A. Fernández-Mayoralas, J. Org. Chem., 1998, 63, 27192723; (b) M. Sandgren, G. I. Berglund, A. Shaw, J. Stahlberg, L. Kenne, T. Desmet and C. Mitchinson, J. Mol. Biol., 2004, 342, 1505-1517; (c) J. Buckingham, J. A. Brazier, J. Fisher and R. Cosstick, Carbohydr. Res., 2007, 342, 16-22; (d) K. Young-Wan, A. L. Lovering, C. Hongming, T. Kantner, L. P. McIntosh, N. C. J. Strynadka and S. G. Withers, J. Am. Chem. Soc., 2006, 128, 2202-2203, as well as ref. $1 c$.

3 For representative examples, see: (a) R. T. Dere and X. Zhu, Org. Lett., 2008, 10, 4641-4644; (b) C. O'Reilly and P. V. Murphy, Org. Lett., 2011, 13, 5168-5171; (c) X. Zeng, R. Smith and X. Zhu, J. Org. Chem., 2013, 78, 4165-4170.

4 C. A. De Leon, P. M. Levine, T. W. Craven and M. R. Pratt, Biochemistry, 2017, 56, 3507-3517.

5 N. Martínez-Sáez, J. Castro-López, J. Valero-González, D. Madariaga, I. Compañón, V. J. Somovilla, M. Salvadó, J. L. Asensio, J. Jiménez-Barbero, A. Avenoza, J. H. Busto, G. J. L. Bernardes, J. M. Peregrina, R. Hurtado-Guerrero and F. Corzana, Angew. Chem., Int. Ed., 2015, 54, 9830-9834.

6 M. K. Tarrant, H.-S. Rho, Z. Xie, Y. L. Jiang, C. Gross, J. C. Culhane, G. Yan, J. Qian, Y. Ichikawa, T. Matsuoka, N. Zachara, F. A. Etzkorn, G. W. Hart, J. S. Jeong, S. Blackshaw, H. Zhu and P. A. Cole, Nat. Chem. Biol., 2012, 8, 262-269.

7 Z. Amso, S. W. Bisset, S.-H. Yang, P. W. R. Harris, T. H. Wright, C. D. Navo, M. L. Patchett, G. E. Norris and M. A. Brimble, Chem. Sci., 2018, 9, 1686-1691.

8 G. E. Norris and M. L. Patchett, Curr. Opin. Struct. Biol., 2016, 40, 112-119.

9 J. C. Maynard, A. L. Burlingame and K. F. Medzihradszky, Mol. Cell. Proteomics, 2016, 15, 3405-3411.

10 (a) M. R. Levengood and W. A. van der Donk, Nat. Protoc., 2006, 1, 3001-3010; (b) D. P. Galonić, W. A. van der Donk and D. Y. Gin, Chem.-Eur. J., 2003, 9, 5997-6006.

11 (a) D. A. Thayer, H. N. Yu, M. C. Galan and C. H. Wong, Angew. Chem., Int. Ed., 2005, 44, 4596-4599; (b) X. M. Zhu and R. R. Schmidt, Chem.-Eur. J., 2004, 10, 875-887; (c) S. Knapp and D. S. Myers, J. Org. Chem., 2002, 67, 29952999; (d) D. P. Galonić, W. A. van der Donk and D. Y. Gin, J. Am. Chem. Soc., 2004, 126, 12712-12713.

12 S. B. Cohen and R. L. Halcomb, Org. Lett., 2001, 3, 405-407. 13 G. J. L. Bernardes, E. J. Grayson, S. Thompson, J. M. Chalker, J. C. Errey, F. El Oualid, T. D. W. Claridge and B. G. Davis, Angew. Chem., Int. Ed., 2008, 47, 2244-2247.

14 D. Crich and F. Yang, J. Org. Chem., 2008, 73, 7017-7027.

15 E. Calce, G. Digilio, V. Menchise, M. Saviano and S. De Luca, Chem.-Eur. J., 2018, 24, 6231-6238.
16 A. Dondoni, A. Massi, P. Nanni and A. Roda, Chem.-Eur. J., 2009, 15, 11444-11449.

17 (a) D. Ellis, S. E. Norman and H. M. I. Osborn, Tetrahedron, 2008, 64, 2832-2854; (b) L. Lázár, M. Csávás, M. Herczeg, P. Herczegh and A. Borbás, Org. Lett., 2012, 14, 4650-4653.

18 Besides thioanalogues of glycosylated tyrosines, only one example of peptide arylthioglycoside has been reported to our knowledge: A. Novoa, S. Barluenga, C. Serba and N. Winssinger, Chem. Commun., 2013, 49, 7608-7610.

19 P. Lafite and R. Daniellou, Nat. Prod. Rep., 2012, 29, 729-738. 20 (a) A. Halim, G. Brinkmalm, U. Rüetschi, A. WestmanBrinkmalm, E. Portelius, H. Zetterberg, K. Blennow, G. Larson and J. Nilsson, Proc. Natl. Acad. Sci. U. S. A., 2011, 108, 11848-11853; (b) S. Y. Vakhrushev, C. Steentoft, M. B. Vester-Christensen, E. P. Bennett, H. Clausen and S. B. Levery, Mol. Cell. Proteomics, 2013, 12, 932-944.

21 J. C. Trinidad, R. Schoepfer, A. L. Burlingame and K. F. Medzihradszky, Mol. Cell. Proteomics, 2013, 12, 34743488.

22 S. L. King, H. J. Joshi, K. T. Schjoldager, A. Halim, T. D. Madsen, M. H. Dziegiel, A. Woetmann, S. Y. Vakhrushev and H. H. Wandall, Blood Adv., 2017, 1, 429-442.

23 (a) T. Jank, X. Bogdanović, C. Wirth, E. Haaf, M. Spoerner, K. E. Böhmer, M. Steinemann, J. H. Orth, H. R. Kalbitzer, B. Warscheid, C. Hunte and K. Aktories, Nat. Struct. Mol. Biol., 2013, 20, 1273-1280; (b) T. Jank, S. Eckerle, M. Steinemann, C. Trillhaase, M. Schimpl, S. Wiese, D. M. van Aalten, W. Driever and K. Aktories, Nat. Commun., 2015, 6, 7807.

24 (a) A. Bruneau, J.-D. Brion, M. Alami and S. Messaoudi, Chem. Commun., 2013, 49, 8359-8361; (b) E. Brachet, J.-D. Brion, S. Messaoudi and M. Alami, Adv. Synth. Catal., 2013, 355, 477-490; (c) E. Brachet, J.-D. Brion, M. Alami and S. Messaoudi, Adv. Synth. Catal., 2013, 355, 2627-2636; (d) E. Brachet, J.-D. Brion, M. Alami and S. Messaoudi, Chem.-Eur. J., 2013, 19, 15276-15280; (e) R. A. A. AlShuaeeb, G. Galvani, G. Bernadat, J.-D. Brion, M. Alami and S. Messaoudi, Org. Biomol. Chem., 2015, 13, 1090410916; $(f)$ A. Chabrier, A. Bruneau, S. Benmahdjoub, B. Benmerad, S. Belaid, J.-D. Brion, M. Alami and S. Messaoudi, Chem.-Eur. J., 2016, 22, 15006-15010; $(g)$ T. T. H. Luong, J.-D. Brion, E. Lescop, M. Alami and S. Messaoudi, Org. Lett., 2016, 18, 2126-2129; (h) R. A. A. AL-Shuaeeb, D. Montoir, M. Alami and S. Messaoudi, J. Org. Chem., 2017, 82, 6720-6728.

25 A. Bruneau, M. Roche, A. Hamze, J.-D. Brion, M. Alami and S. Messaoudi, Chem.-Eur. J., 2015, 21, 8375-8379.

26 Fort the preparation of the precatalyst, see: $(a)$ N. C. Bruno, M. T. Tudge and S. L. Buchwald, Chem. Sci., 2013, 4, 916-920, for a review related to the use of $\mathrm{Pd}^{-\mathrm{G}_{3}}$ precatalysts, see: $(b)$ A. Bruneau, M. Roche, M. Alami and S. Messaoudi, ACS Catal., 2015, 5, 1386-1396.

27 S. V. Moradi, W. M. Hussein, P. Varamini, P. Simerska and I. Toth, Chem. Sci., 2016, 7, 2492-2500.

28 The coupling of 1a and 2a was also performed in the presence of different other Pd-based catalysts such as 
$\mathrm{Pd}(\mathrm{OAc}) / \mathrm{SPhos}, \mathrm{Pd}(\mathrm{OAc}) / \mathrm{XPhos}$ and $\mathrm{Pd}(\mathrm{OAc})_{2} /$ disodium 2aminopyrimidine-4,6-diol. However, none of the catalysts did produce the desired product 3a even at high loading (see ESI, $\uparrow$ P5).

29 In all cases herein reported, when the peak corresponding to the anomeric proton could be clearly identified on the ${ }^{1} \mathrm{H}$ NMR spectrum, it showed characteristic $J_{1,2}$ coupling constants indicating the retention of the expected anomeric configuration in the glycosylated products.

30 (a) I. Valverde, F. Lecaille, G. Lalmanach, V. Aucagne and A. F. Delmas, Angew. Chem., Int. Ed., 2012, 51, 718-722; (b) V. Aucagne, I. E. Valverde, P. Marceau, N. Dendane, M. Galibert and A. F. Delmas, Angew. Chem., Int. Ed., 2012, 51, 11320-11324; (c) M. Beltramo, V. Robert, M. Galibert, J.-B. Madinier, P. Marceau, H. Dardente, N. De Roux, D. Lomet, A. F. Delmas, A. Caraty and V. Aucagne, J. Med. Chem., 2015, 58, 3459-3470; (d) M. Galibert, V. Piller, F. Piller, V. Aucagne and A. F. Delmas, Chem. Sci., 2015, 6, 3617-3623; (e) M. Galibert, M. Wartenberg, F. Lecaille, A. Saidi, S. Mavel, A. Joulin-Giet, B. Korkmaz, D. Brömme, V. Aucagne, A. F. Delmas and G. Lalmanach, Eur. J. Med. Chem., 2018, 143, 201-210.

31 C. Decourt, V. Robert, K. Anger, M. Galibert, J.-B. Madinier, H. Dardente, D. Lomet, A. F. Delmas, A. Caraty, A. Herbison, X. Liu, G. Anderson, V. Aucagne and M. Beltramo, Sci. Rep., 2016, 6, 26908.

32 (a) M. J. Orsini, M. A. Klein, M. P. Beavers, P. J. Connolly, S. A. Middleton and K. H. Mayo, J. Med. Chem., 2007, 50, 462-471; (b) A. E. Curtis, J. H. Cooke, J. E. Baxter, J. R. C. Parkinson, A. Bataveljic, M. A. Ghatei, S. R. Bloom and K. G. Murphy, Am. J. Physiol.: Endocrinol. Metab., 2010, 298, E296-E303.

33 Proteomic studies showed that the precursor of KP10, KISS1, can be post-translationally modified by phosphorylation at this Tyr residue. See: L. M. Brill, A. R. Salomon, S. B. Ficarro, M. Mukherji, M. Stettler-Gill and E. C. Peters, Anal. Chem., 2004, 76, 2763-2772.

34 N. Nishizawa, Y. Takatsu, K. Sumano, A. Kiba, J. Ban, S. Tsutsumi, H. Matsui, S. I. Matsumoto, M. Yamaguchi, Y. Ikeda, M. Kusaka, T. Ohtaki, F. Itoh and T. Asami, J. Med. Chem., 2016, 59, 8804-8811.

35 G. F. Springer, J. Mol. Med., 1997, 75, 594-602.

36 S. J. Gendler, C. A. Lancaster, J. Taylor-Papadimitriou, T. Duhig, N. Peat, J. Burchell, L. Pemberton, E. N. Lalani and D. Wilson, J. Biol. Chem., 1990, 265, 15286-15293.

37 C. Sihlbom, I. van Dijk Härd, M. E. Lidell, T. Noll, G. C. Hansson and M. Bäckström, Glycobiology, 2009, 19, 375-381.
38 (a) V. Lakshminarayanan, P. Thompson, M. A. Wolfert, T. Buskas, J. M. Bradley, L. B. Pathangey, C. S. Madsen, P. A. Cohen, S. J. Gendler and G.-J. Boons, Proc. Natl. Acad. Sci. U. S. A., 2012, 109, 261-266; (b) M. K. Hossain and K. A. Wall, Vaccines, 2016, 4, 25.

39 (a) V. Lakshminarayanan, P. Thompson, M. A. Wolfert, T. Buskas, J. M. Bradley, L. B. Pathangey, C. S. Madsen, P. A. Cohen, S. J. Gendler and G. J. Boons, Proc. Natl. Acad. Sci. U. S. A., 2012, 109, 261-266; (b) K. Yamamoto, T. Ueno, T. Kawaoka, S. Hazama, M. Fukui, Y. Suehiro, Y. Hamanaka, Y. Ikematsu, K. Imai, M. Oka and Y. Hinoda, Anticancer Res., 2005, 25, 3575-3579.

40 V. Rojas-Ocáriz, I. Compañón, C. Aydillo, J. Castro-Lopez, J. Jiménez-Barbero, R. Hurtado-Guerrero, A. Avenoza, M. M. Zurbano, J. M. Peregrina, J. H. Busto and F. Corzana, J. Org. Chem., 2016, 81, 5929-5941.

41 J. A. Speir, U. M. Abdel-Motal, M. Jondal and I. A. Wilson, Immunity, 1999, 10, 51-61.

$42 \mathrm{~N}$-Terminal biotinylation of $7 \mathrm{a}$ by reaction with biotin sulfoNHS ester under standard conditions led to a mixture of the expected mono-biotinylated together with non- and multi-biotinylated species, despite the absence of Lys residues in the sequence. We attribute these results to the formation of Ser/Thr esters, and optimized conditions for $7 \mathbf{a}, 7 \mathbf{b}, \mathbf{8 c}$ and $8 \mathbf{f}$ to avoid such over-biotinylation, see ESI $\dagger$ for details.

43 R. Gibadulli, D. W. Farnswort, J. J. Barchi and J. C. Gildersleeve, ACS Chem. Biol., 2017, 12, 2172-2182.

44 (a) M. Ibba, P. Kast and H. Hennecke, Biochemistry, 1994, 33, 7107-7112; (b) P. Kast and H. Hennecke, J. Mol. Biol., 1991, 222, 99-124; (c) D. Kiga, K. Sakamoto, K. Kodama, T. Kigawa, T. Matsuda, T. Yabuki, M. Shirouzu, Y. Harada, H. Nakayama, K. Takio, Y. Hasegawa, Y. Endo, I. Hirao and S. Yokoyama, Proc. Natl. Acad. Sci. U. S. A., 2002, 99, 9715-9723; (d) K. Kirshenbaum, I. S. Carrico and D. A. Tirrell, ChemBioChem, 2002, 3, 235-237; (e) J. W. Chin, T. A. Cropp, J. C. Anderson, M. Mukherji, Z. Zhang and P. G. Schultz, Science, 2003, 301, 964-967; $(f)$ L. Wang, J. Xie, A. A. Deniz and P. G. Schultz, J. Org. Chem., 2003, 68, 174-176; (g) K. Kodama, S. Fukuzawa, H. Nakayama, T. Kigawa, K. Sakamoto, T. Yabuki, N. Matsuda, M. Shirouzu, K. Takio, K. Tachibana and S. Yokoyama, ChemBioChem, 2006, 7, 134-139.

45 T. J. Wadzinski, A. Steinauer, L. Hie, G. Pelletier, A. Schepartz and S. J. Miller, Nat. Chem., 2018, 10, 644652 . 